\title{
Some important aspects of rock mechanics and geomechanics
}

\author{
Oleksii Voloshyn ${ }^{1}$, and Oleh Riabtsev ${ }^{1, *}$ \\ ${ }^{1}$ Institute of Geotechnical Mechanics named by N. Poljakov of National Academy of Sciences of \\ Ukraine, 49005, Dnipro, Simferopolska Str., 2a, Ukraine
}

\begin{abstract}
This work considers the analysis of important aspects of rock mechanics, such as the variability of the mechanical properties of rocks under the samples testing, the continuity of the rock mass and the deformation beyond the elastic limit, which have a great influence on the accuracy and reliability when conducting geomechanical studies of the rock mass during coal mining. The main methods for solving geomechanical problems are shown.
\end{abstract}

\section{Introduction}

One of the priority scientific disciplines of mining is rock mechanics, which appeared in the previous century in connection, first of all, with the needs of a purely applied nature, and subsequently received rapid development both in the USSR and abroad.

In [1], the authors have noted that rock mechanics has achieved milestones such as an initial accumulation and synthesis of the physicomechanical properties of rocks, visual observations of the state of underground mine workings and engineering structures; obtaining the first empirical formulas linking their stability with the physicomechanical properties of rocks, as well as the active use of continuum mechanics models, theories of elasticity and plasticity for the mathematical description of complex natural and technical objects.

In recent decades, experimental methods of diagnosing and controlling the stress-strain state of rock mass have also been developed, and on the basis of rock mechanics, "... the contours of geomechanics have become visible, as a new scientific discipline in the spectrum of earth sciences ..." [1]. This was encouraged, first of all, by discoveries in this field, obtained on the basis of experimental research methods in a number of scientific organizations in our country and abroad, including Institute of Geotechnical Mechanics named by N. Poljakov (IGTM) of National Academy of Sciences (NAS) of Ukraine.

There are a huge number of results of determining the main indicators and characteristics of the mechanical properties of rocks that form the basis of rock mechanics and geomechanics, which are necessary as basic data for studying and calculating various elements of geotechnologies in mining operations.

The author of this article considers it necessary to additionally pay attention to some characteristic features of the methodological plan, which must be taken into account when

*Corresponding author: o.ryabtsev1973@gmail.com 
solving the above problems.

\section{Variation of mechanical properties of rocks during samples tests}

To assess the rocks rupture strength, the parameter of static uniaxial compressive strength $R_{\mathrm{c}}$, determined on rock samples, is most often used.

Indicators of strength limit of various materials, including metals for which they are "passport" values (immanent characteristics) are given in many scientific and technical publications, reference books, etc. Is there a possibility of a similar interpretation of the concept of "limit" in relation to rocks?

The results of almost century-old research of this issue by domestic and foreign experts are summarized and analyzed in [2]. The result is definitely negative: the strength characteristics cannot be considered as immanent values of the true strength of the rock.

The strength index obtained by testing samples of a certain size, in general, cannot be considered only as a rock characteristic, but it is a complex characteristic of the interaction (for example, a pair: a certain size and quality sample plus a press), carried out at some stable parameters (loading rates, temperature, presence or absence of lubricant, etc.). For example, the variation coefficients of the strength limit of rocks under compression for the Pavlograd region mines conditions (in free form) are the following: for sandstones $K_{v a r}=$ $35 \%$ under an average value of $R_{\mathrm{c}}=45.1 \mathrm{MPa}$; for aleurolite $K_{v a r}=94.9 \%$ under $R_{\mathrm{c}}=$ $42.9 \mathrm{MPa}$; for mudstones at $R_{\mathrm{c}}=21.9 \mathrm{MPa} K_{\text {var }}=30.1 \%$ [3].

A scale of stability (accuracy) of mining and technological indicators and engineering calculations of the basic processes of mining technology is given in [2], in which the coefficient of variation is a decisive criterion, which value exceeds $40 \%$. It was shown [4] that the spread of long-term strength values is greater than the so-called instantaneous strength, and increases for strong rocks $\left(R_{\mathrm{c}}>50 \mathrm{MPa}\right)$ in 1.2 times, and for weak ones - in 1.4 times.

An important characteristic of the rock is the indicator of temporary resistance to uniaxial tension $R_{\mathrm{p}}$, which correlates with the tear resistance.

In [5], the results of determining the $R_{\mathrm{p}}$ value by six GOST methods are presented. The root-mean-square relative deviations from the general means for granite, sandstone and limestone are respectively $\pm 44.1 \%, \pm 58.9 \%$ and $\pm 63.0 \%$. In general, for all rocks, the overall average value of the coefficient of leading to the direct separation was $242.4 \%$.

The high instability of the indicators of the rocks strength properties leads to the fact that using the indicators in calculations by the methods of classical mechanics, it is necessary to resort to averaging the numbers, and these numbers are considered as constant characteristics of some fictitious continuum. However, if such an averaging is valid only for linear relationship, then it is fundamentally unsuitable for the determined characteristics of the rock that do not obey the additivity rule.

So, it can be stated that due to the strong variability and susceptibility to the influence of many factors, including unreliably predicted and unreliably quantified factors, the results of determining the strength properties of rocks by samples tests do not have the properties of technical constants resulting from similar samples tests of other materials. This is the most important specific feature of rocks as objects for determining strength properties by testing samples using conventional methods of the science of resistance of materials.

The main characteristic of the deformation properties of rocks in contrast to other materials is the modulus of deformation $E_{d}$. Within the limits of linear deformation, the module $E$ has the physical meaning of the elastic modulus $E_{e}$. Unlike metals, the modulus $E_{e}$ for rocks is highly conditional, since residual deformations can occur at relatively low stresses. The numerical values of $E_{d}$ are always smaller than $E_{e}$, which is determined by the 
share of plastic deformation in the pre-limit part of the stress-strain diagram. Rocks belong to the group of physically anisotropic materials that are not equally resistant to compression - stretching. Therefore, the value of $E_{d}$ depends on the direction of the load.

The computation scheme of the deformation characteristics of the rock with given lithological difference and a certain strength limit under uniaxial compression $R_{\mathrm{c}}$ includes two basic operations, the first of which is the determination of the elastic modulus (linear) $E_{\mathrm{e}}$. Its value can be established from any source and, first of all, according to the data of processing of the geological explorations at the sites. However, according to these data, as well as in geological forecasts for a specific mining site, the deformation properties of the components of the rock mass are extremely rare. Among the physical mechanical properties of rocks that are indicated in the listed documents, the most reliable (mandatory) indicator is the value of strength limit under uniaxial compression of rocks composing stratigraphic columns. Therefore, in the absence of other information, such as data of special studies of the deformation characteristics of rocks within the mining area, the available correlation dependencies between rock strength limit under uniaxial compression (argument) and elastic modulus (function) can be used.

Another important deformation characteristic is the coefficient of transverse deformation $\mu$, which is the absolute value of the ratio of transverse deformation $\varepsilon^{I}$ to longitudinal deformation $\varepsilon$ under conditions of uniaxial compression or tension.

In the linear deformation, the coefficient of transverse deformation is called the Poisson ratio and is a constant value. Outside of linear deformation $\mu \neq$ const.

The Poisson ratio value does not affect the qualitative picture of the stress-strain state of the massif and very slightly affects the quantitative side of this state. So, the error is only 10 $-15 \%$ under the replacement $\mu=0.3$ (the most common value for rocks) to $\mu=0.5$, that is within the accuracy of the experimental determination of this parameter [4]. To solve the elastic-plastic problems and problems that take into account the rock creep, it is more reasonable to use the Poisson ratio equal to 0.5 .

It is known that most rocks do not obey strictly the law of linear deformation [7]. For example, it has been established that about $90 \%$ of the productive rock mass of Western Donbass have nonlinear creep, approximately $80 \%$ of this productive rock mass obey a substantially nonlinear law of deformation [8]. At the same time, rocks with compressive strength (8 - 30) MPa shows deformation nonlinearity under 25 - 35\% of destructive loads, and with strength (30 - 50) MPa shows deformation nonlinearity under $40-45 \%$.

As noted in [8], "... there cannot be a consistent calculating method of rock displacements near the workings based on elastic and temporary deformation, which would not be related to the considering the improbably large dimensions of its influence zone when trying to describe large displacements of the working contour ..."

The features of non-linear deformation of rocks can be considered as one of the stages of complication and increasing the level of adequacy of design schemes in relation to the real conditions of mining.

Nonlinearity of Pavlohrad sedimentary rock formation is most adequately described using the form of connection between stresses and strains in the form of area tangent for the case of a soft deviation from Hooke's law [8]. Available information suggests that the value of $E_{d}$ is in the range of $0.55-0.38$ from $E_{e}$.

In [4], the results of large-scale studies of the rheological properties of rocks of the sedimentary complex, carried out in IGTM NAS of Ukraine, are presented, on the basis of which their classification has been developed. The advantage of this classification is the ability to determine the indicators of the rheological properties of rocks taking into account the macroscopic and petrographic features of each lithological difference. 


\section{A rock mass and its continuity}

A rock mass is a complex physical medium with a number of specific features that largely determine its mechanical condition.

The main reasons causing these features are the fracturing of the massif (natural and artificial), the heterogeneity of the material composition (layering, shale, etc.), as well as its stress state. All this together leads to the fact that in the most general case, a rock mass is a physically discrete, inhomogeneous, anisotropic medium, with non-linear, temporal mechanical processes of deformation.

Obviously, the mathematical description (as a physical reproduction) of such an environment is extremely complex, and the solving the specific problems by ordinary analytical methods is almost impossible due to insurmountable mathematical difficulties.

Due to this circumstance, the studying of mechanical processes in a rock mass by analytical methods based on the general principles of continuum mechanics uses idealized image as an object of research instead of an actual rock mass. This idealized image is called the geomechanical model.

Naturally, the indicators of the physicomechanical properties of rocks in the massif differ from similar ones obtained on samples. First of all, this is a consequence of the socalled scale factor. The essence of the scale factor is described in numerous studies, as well as the methods developed for taking into account massif structural weakening for practical use in geomechanical calculations [3, 5, 7, $9-14]$. Among the above mentioned works, in our opinion, the proposals of the authors $[3,10]$ are the most physically based.

In [3], the coefficients of structural weakening of the massif are calculated based on the results of practical tests, observations and inverse calculations. The authors of this work use the characteristics of the massif and the magnitude of the compressive strength of the rock specimen from this massif as arguments.

The authors of the work [10] state that the structural and mechanical features of the rock mass accounting, including its macro-fracturing, is possible using the method of replacing a real massif to idealized one, but with mechanical characteristics equivalent to the real massif.

In this approach, the qualitative correspondence of the stress-strain state between the real massif and its model is violated, but the final quantitative results at the given points coincide. To determine the equivalent value of the strain modulus of a massif, the K.V. Ruppeneyt [15] method is used. This method is developed in detail and widely tested. It leads to take into account the following parameters of the real massif as source data: the number of crack systems, the width of crack opening, the relative area of rock contacts in cracks, the average distance between two cracks in each system, the angle between the directions of the cracks of each system and the horizontal plane.

Using this method allows to obtain the values of the shifts of working contours, that are adequate to natural ones. For example, the contour of a circular working with a radius of $2 \mathrm{~m}$, traversed in aleurolite with $R_{\mathrm{c}}=28 \mathrm{MPa}$ with chaotic fracturing, with a crack opening of $0.1 \mathrm{~cm}$ and a distance between them of $60 \mathrm{~cm}$ will shift in the vertical plane by $330 \mathrm{~mm}$, and under a distance between them of $40 \mathrm{~cm}-910 \mathrm{~mm}$.

Besides the structural-mechanical weakening, the massif is also affected by the humidity and depth of the geotechnological facility, for which a specific mining engineering problem is being solved. These factors can be taken into account in accordance with the recommendations $[3,14]$.

In general, the authors noted [11]: “ $\ldots$ speaking of the stress-strain condition of the rocks around the workings, we assume that in all formulas describing the properties of rocks, the $R_{\mathrm{c}}$ obtained in laboratory experiments ..." should be replaced by the $R_{\mathrm{c}}$, which takes into account the coefficient of structural weakening of the rock in the massif and the stress- 
rupture strength. The same should be done with the elastic modulus $E_{e}$ and the Poisson's ratio. Cases where the experimental data of laboratory experiments on rock samples are used directly, without corrections, must be stipulated.

\section{Geotechnological problems solutions}

Now, the most common geomechanics problems solution is the method of continuum mechanics. One of the apologists of classical continuum mechanics [16, 17] L.I. Sedov said: "We introduce the concept of a continuum. All bodies are made up of individual particles, but there are many of them in any essential volume, therefore the body can be approximately considered as a medium filling the space in a continuous way. This idealization, in particular, is necessary ... in order to use the apparatus of continuous functions, differential and integral calculus in the study of the movement of deformable bodies".

Continuum mechanics studies the motion and equilibrium of deformable solids. A model of real bodies in continuum mechanics is a continuous medium in which all material characteristics are continuous functions of spatial coordinates and time.

The difficulty of creation of specific models is to establish a system of variables determining the medium and a system of relations between them, as well as various additional conditions that allow us to formulate mathematical problems of the laws of change of all the mechanical characteristics of a continuous medium under its deformation.

In particular models of a continuum, general physical laws and certain additional hypotheses of a phenomenological nature are used, based on theoretical background and experimental data.

To solve the problems of continuum mechanics, boundary and edge conditions must be formulated. It is not possible to obtain a mathematical problems solution in the class of continuous functions for all of continuum models, sometimes it is necessary to find a solution in the class of distributions with discontinuities, in addition the medium parameters on the both surfaces of the discontinuity must be bound by certain conditions.

One of the main problems of continuum mechanics is the adequate reduction of mechanical problems to mathematical problems, because in many cases, even relatively simple, mathematical problems of continuum mechanics are unsolvable by mathematical tools.

In [18], it was shown that the hypotheses of the elasticity theory have a good agreement with the behavior of metal structural components under load. This is understandable, because in everyday practice, metal structures experience small deformations. It seems reasonable to use this fact for some simplifications, which are quite acceptable for solving problems.

Thus, the classical elasticity theory is a theory of elastic medium, linearized near the natural state. In addition, it is assumed that the medium is homogeneous and isotropic relatively to its natural state, and this is free from stresses. This is an asymptotic of small perturbation theory.

The main thing in the mechanics of a continuous deformed body is assumption that the medium is devoid of structure and has an entirety with a continuous distribution of substance, the so-called continuum. This hypothesis allows us to consider stresses and strains as continuous and deformable functions of the coordinates of body points. It is also assumed that any sufficiently small, so-called elementary, volumes of the medium have the same physical and mechanical properties.

The real rock mass, as a natural system, has a high degree of disorder, in which, depending on the size of the study area, five large-scale levels of heterogeneity can be considered: ultramicroscopic, microscopic, mesoscopic, macroscopic, megascopic. 
However, in [8] it is convincingly shown that "... It is impossible to obtain the calculated values of the displacement of the working contours in tens of centimeters (that is adequate to the actual conditions of mining), assuming that the rock is deformed within continuity ...".

Certain difficulties of modeling geomechanical processes by using the basic principles of continuum mechanics can be eliminated by using numerical simulation methods. This is an effective research method, which possibilities are limited only by the level of adequacy of the original deformation models, created on the basis of the generalities of continuum mechanics.

The current level of modeling and computing techniques allows using a computational experiment to investigate the behavior of complex objects, analyze the interaction between parts of the modeled object, the interaction between the object and the environment, identify possible negative phenomena and effects (for example, shifts, dips of large massifs, the impact of mining to the stress-strain state of the rock mass), to predict their possible development.

Today, such a numerical experiment is the solution of mathematical problems (systems of partial differential equations) that describe the considering phenomena. To solve these systems, they use a software that implements specialized finite-difference or finite-element computational schemes $[19,20]$.

The spectrum of software that uses a mathematical basis of the finite element method (FEM) is extremely wide - from small specialized programs to powerful systems that combine the modeling capabilities of several interrelated non-linear processes with a modern graphical interface and built-in support for standards for preparing project documentation.

One of the directions of FEM evolution is developed in the V.M. Glushkov Institute of Cybernetics of NAS of Ukraine methods of using discontinuous functions classes for making mathematical models of complex processes in multicomponent continuous mediums and creation the computational schemes of a higher order of accuracy of their numerical discretization.

In this institute, software for modeling spatial processes in inhomogeneous threedimensional medium, which is based on the developed design schemes, is elaborated. One of this software features is using the parallel computing, which allows solving problems with a large number of degrees of freedom (several million or more). Created multiprocessor computer complexes SCIT-3 and SCIT-4 are used as computing resources.

S.P. Timoshenko [6] wrote that elasticity theory is able to give a complete and strict solution only for the simplest cases. He noted that the analytical methods that had prevailed in the science of strength of materials for a long time, in many cases, are inadequate to solve a number of technical problems. Further, Timoshenko wrote: "The wide-scale introduction of the experiment has brought a fresh stream to this area".

It is known that the strength properties of ordinary materials are estimated by the characteristics of the strength of materials that are the part of the mathematical apparatus of classical mechanics (theories of elasticity and plasticity), which "rigorous" calculation methods are used. It is necessary to clarify the real possibilities of "rigorous" methods in this field to define whether such characteristics are appropriate for assessing the rupture resistance of rocks. It is impotent to know the level of significance of the factors that "prevent" the use of "rigorous" calculation methods for solving various mining engineering problems.

There is known [6] the "incorrectness" of rock sample tests in the mode of specified loads, which does not at all correspond to the actual mechanical condition of rocks in the massif, where they work in the mode of specified deformations. The mathematical apparatus of the resistance of materials was created precisely for the construction industry 
needs (technology and technique), which work precisely in the mode of specified loads.

It is necessary to note that "obstructive factors" are the features of properties of rock as investigated project, namely, very strong variability (variation) because of influence of a large number of factors: such as heterogeneities of several orders of magnitude, anisotropy of several orders of magnitude, other components of the rock conditions in massif, scale factor, etc.

Taken into account this circumstances, L.I. Baron suggested to use the principle of invariant correlation ratios as a scientific and methodological basis for calculations that use the criteria of the mining and technological properties of rocks. He thinks that the calculation of the basic processes of mining technology is practically reduced to finding for each specific process a rational algorithm suitable for various rocks - all or some group. It is proposed to use integral indicators for a quantitative assessment of the properties of rocks in the calculations. The relation between rock properties expressed collectively in the integral index and the parameters of the geomechanical process in a rock mass has a correlation nature. The acceptability of the algorithm is determined by the constancy (invariance) of this ratio for different rocks. That is why its name is "the principle of invariant correlation relations".

The main feature of the geomechanical processes of rock mass mining, primarily exploration of sedimentary formation by the underground method, is the destruction of rocks of a covering series of different intensity on the huge aria of mine fields, especially in the conditions of seam working by long working face system with complete roof collapse. This leads to large or, during the development of the multiple seams to repeated sedimentations and displacements of seam workings, changes in their condition and properties at a distance of tens and hundreds of meters from the worked seam, changes in the condition and properties of the underlying series. The duration of the period of attenuation of the intensity of geomechanical processes is often measured over the years and ends in different parts of the massif at different time intervals. So, mining of multiple seams has to be carried out in modified, fractured, partially destroyed massifs. The main types of rock mass are non-continuous, divided mediums with variable scales and intensity of violations. As a result, there are very complex tasks of different classes, that predetermine different solution methods. Problems of purely continuous medium have incomparably smaller distribution in comparison with problems of non-continuous (discrete) medium.

The complexity of rocks and massifs mechanics also limits the range of problems where phenomenological approaches are applicable. Solving problems of discontinuous (separated) medium, that are rock mass in most cases, should be regarded only as some kind of raw data useful for finding approximate solutions. The difference between the results obtained by this method and, for example, by the method of volume models, can reach from one to five orders of magnitude or more [21].

Therefore, one of the most important tasks of rock and rock mass mechanics is the development of mechanics of discontinuous medium, which will also allow solving combined problems.

It is necessary to develop the applications of continuum mechanics, which are far from being exhausted. It is enough to point out the encouraging results of the calculations of the reference pressure in laminate rocks (with different deformation properties) using the Lagrange variational method, as well as the results of S.A. Khristianovich, G.I. Barenblat, A.G. Protosenya and others.

Particular hypotheses of rock pressure are still used to determine the load on the lining, although the area of their application has been significantly reduced when the mining of minerals goes to great depths.

Probability statistical methods are widely used in rock mechanics: statistical processing 
and evaluation of the properties of rocks and massifs; probabilistic models for assessing the strength of solid, layered and block massifs; probabilistic methods and models for assessing the reliability of elements of massifs, mine workings and underground structures; statistical models of destruction.

The analysis of methods for modeling the rock mass for prediction the rock pressure showed the complexity and the huge variety of mechanical and mathematical models. Such a diversity of models is a natural consequence of the diversity of mining and geological conditions and properties of the rock mass.

The hypotheses of rock pressure on an experimental basis also include hypotheses of a granular medium, a fracturing medium, and fractal analysis of plates (beams).

The last hypothesis, in our opinion and the results of its practical use, most adequately represents the geomechanical model of a laminated, multimodular massif.

The slab hypothesis is a further development of the beam hypothesis. The hypothesis of beams is known for about a hundred years. Prof. V.D. Slesarev developed this hypothesis most actively among domestic scientists. The hypothesis of beams in various variants was stated in the well-known works of many scientists from different countries (Schultz, Frind, Eckard, Curzon, Phillipson, Slesarev, and others).

Prof. D.S. Rostovtsev, prof. V.D. Slesarev, V. Stockie and G. Herman and others suggested that the roof, composed from laminate rocks, works like a slab.

Prof. V.D. Slesarev clearly formulated the idea that the roof is a slab and gave an approximate method of replacing slabs with an equivalent beam under the equivalent stress and strain conditions. Then this hypothesis was developed [22, 23] and software and technology complex on its base was of a large-scale practical use [24 - 26].

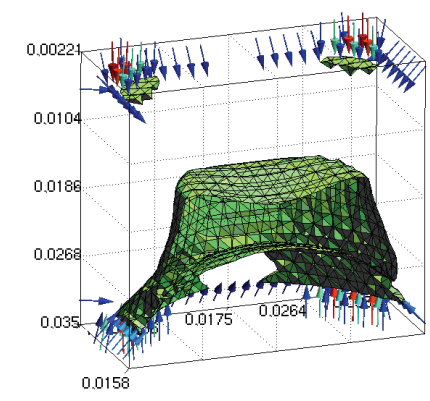

a)

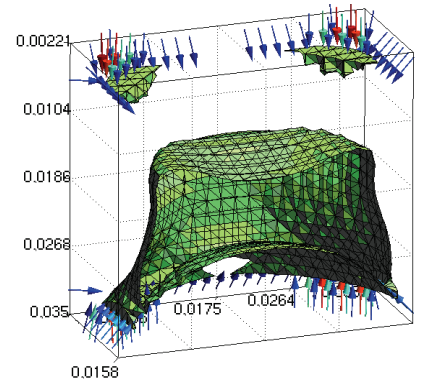

b)

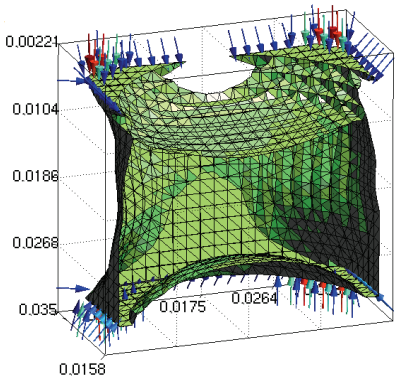

c)

Fig. 1. Distribution of damage at the stages preceding the destruction: a) - damage at the 70th step of load; b) - damage at the 75th step of load; c) - damage at the 80th step of load (moment of destruction).

The authors of [27] tested the theory of fractals and the concept of environmental damage using numerical modeling of the process of destruction of cubic rock specimens for the conditions of rigid fixing of the lower edge, while the upper edge had the ability to move only vertically. The distribution of damage at the stages preceding the destruction is shown in Figure 1.

In Figure 1c, several initially disjoint regions are merged into one percolation cluster. The formation of main cracks along the lines of the maximum gradient (curve lines in Fig. 2) leads to the destruction of the rock sample, which corresponds to the percolationcluster model of damage accumulation. This results correlate well with the results of the works of domestic and foreign authors that the mechanism of destruction of geomaterials has percolation-fractal nature, involving methods of continuum (not necessarily isotropic), the theory of damage (scalar or tensor), the theory of percolation clusters. Therefore, further research in this direction will focus on the use of the theory of damage and fractal analysis 
to solve problems associated with the characteristics of the destruction of sedimentary rocks.

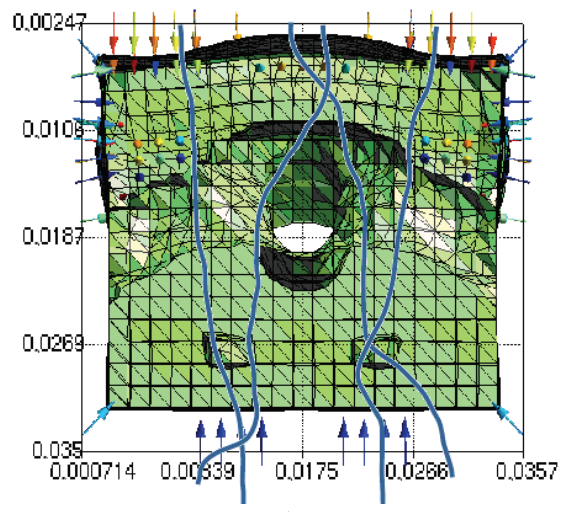

a)

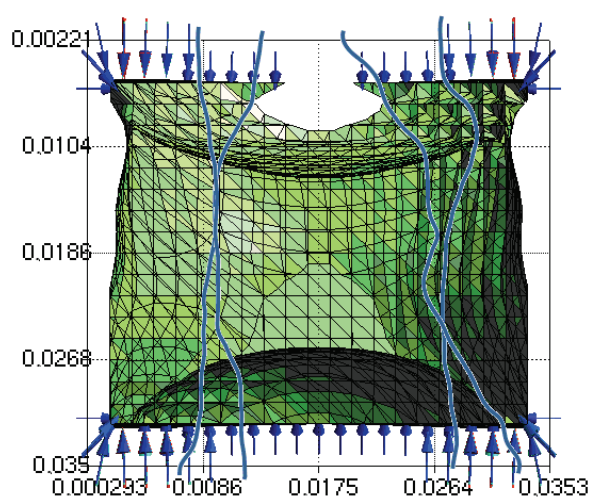

b)

Fig. 2. Formation of main cracks at the time of destruction of rock samples: a) - with non-rigid fixing of the lower base of the sample; b) - with rigid fixing of the lower base of the sample.

\section{Deformation beyond the elastic limit}

As the authors of [11] noted, the most important deformations for practice were developing in the beyond-the-limit sections of the stress-strain diagrams, which opens up the prospect of their consideration for geomechanics. This fact has led to rapid growth of geomechanics since the mid- 60 s of the last century.

A great contribution in obtaining complete stress-strain diagrams was made by both foreign (D. Hobbs, Z. Benyavsky, R. Hooper, S. Krush, M. Pane, etc.) and domestic researchers (V.T. Glushko, V. Vinogradov, I.M. Petuhov, I.A. Baklashov, B.M. Usachenko, G.L. Fisenko, A.M. Linkov, G.G. Litvinsky, B.K. Norel, R.L. Salganik, A.N. Stavrogin, A.G. Protosenya, Yu.M. Kartashov and others), which results were published in numerous works, in particular [3, 8, 10 - 13, 21, 27-28] and others.

In recent years, much attention has been paid to the development of experimental research methods that reproduce the actual conditions of force and kinematic impacts on rocks during mining operations.

The most important real condition of mechanical impact on rocks in the massif is loading in the specified deformation mode, since traditional methods of rock samples testing in the specified load mode do not correspond to the actual mechanical condition of these rock volumes in the massif, where the specified deformation mode is defining [10, 29]. In recent years, methods of testing rocks on presses with high rigidity or equipped with tracking devices have been developed. Such tests provide the mode of specified deformations and allow to plot the so-called full deformation diagrams.

These diagrams characterize the mechanical conditions of rocks in all segments of loading: up to the ultimate strength (pre-limit segment of the diagram); at the level of ultimate strength; beyond the limit of strength, including the segment of residual strength (the out-of-limit segment of the diagram). The resulting information about the mechanical properties of rocks is the most complete and characterizes the actual mechanical condition of the rocks.

The achievement of the maximum bearing strength of the sample under a soft loading mode leads to the formation of main macrocracks in the sample and its destruction. In this case, the carrying capacity of the sample drops to zero without increasing the deformation, i.e. the limiting branch of the deformation diagram is almost vertical. Moreover, the 
destruction has often a dynamic nature with the recession of parts of the destroyed sample. The reason is the accumulation of elastic deformation energy in the elements of the soft loading device and its realization as a kinetic energy during the destruction of the sample, which reduces the value of the maximum load-carrying capacity of the sample and completely distorts the picture of its extreme deformation. Thus, the soft loading mode makes it possible to fix only the maximum carrying capacity of the sample, and not the strength limit of the rock as a material.

In the case of a hard loading mode, the maximum carrying capacity of the sample corresponds to the instantaneous ultimate compressive strength $R_{\mathrm{c}}$. Further, in the deformation segment (the out-of-limiting branch of the diagram), an increase in deformation corresponds to a decrease a carrying capacity to a certain minimum value, called the residual strength of rocks $R_{\mathrm{o}}$. The slope of the out-of-limiting branch of the diagram is characterized by the decay modulus $M$.

The decay module $M$ is the main parameter of extreme deformation and characterizes the tendency of rocks to brittle fracture, which increases with increasing $M$. It should also be noted the Poisson ratio is increasing its value while increasing decay module $M$, i.e. in brittle-destructive rocks there is a large dilatancy than in the rocks, which are destroyed with the plastic deformation, although for some rocks this rule does not work.

Comparison and analysis of the methodological basis of the pre-limit and extreme (outof-limit) deformation of rocks led the researchers to the so-called dynamic paradox. The authors of [11] say that the use of complete equations for extreme deformation is possible only for static problems, because it is fundamentally impossible to write a falling diagram under dynamic loads and the formulation of dynamic problems under the deformation on the falling branch is incorrect and has no physical meaning. Mathematically, hyperbolic equations for changing displacements, that are valid for the pre-limit deformation, turn into elliptic ones; the speed of disturbance propagation becomes imaginary; the usual formulation of dynamic problems is impossible, and arbitrarily small deviations increase indefinitely with time.

Naturally, the question is, how far is it physically meaningful to talk about extreme deformation? After all, any real process occurs in time and is carried out with some small, but finite displacement rates. The "strict" answer to this question, if we do not take into account the structure of the material and the conditions of the experiments, is "no, extreme deformation is mysticism, talking about it is pointless". This is the so-called dynamic paradox.

The author of [30] expresses his opinion even more harshly about the problem of extreme deformation. His summary is as follows. The problem of extreme deformations of materials beyond the strength limit belongs to the sections of fracture mechanics. Using a simple example, the author demonstrates the connection of this problem with parapsychology, that studies phenomena and processes where the causality principle is violated. It is shown that the concept of extreme deformations leads to problems whose solutions do not exist.

The cause of the dynamic paradox from a phenomenological point of view was explained by the authors of [11]. On hard presses, diagrams with falling segments are well reproduced and changed relatively weakly at speeds from $10^{-8}$ to $1 \mathrm{~m} / \mathrm{min}$. Such speeds often take place in practice, and these diagrams are useful and important for practical purposes. Thus, from a phenomenological point of view, the answer to the above question is different: "Under speeds that ensure uniform sample deformation and a diagram with a falling segment on a hard press, the falling segment makes sense for static tasks.

In this case, the task can be considered static if the perturbation rates are within the specified conditions. Otherwise, the perturbations are dynamic, the formulation of boundary-value problem for the falling segment is meaningless and gaps on the front of the 
fracture wave in the rock should be considered.

For many years, IGTM NAS of Ukraine has researched the development of equipment and methods for testing the behavior of lightly metamorphosed rocks at great depths. Different types of stress conditions and loading modes were provided by specially developed simple devices that are installed on a test machine of increased rigidity, which provides characteristics of the out-of-limit behavior of rocks, as well as studies of the properties and patterns of behavior of extremely stressed rocks under deforming conditions of three-axis compression [4, 27 and others].

The results of large-scale studies of the rock behavior in the pre-limit and out-of-limit stages of deformation under the varying all the main influencing factors and conditions, formed the basis for the development of the Guiding regulatory document of the Ministry of Coal Industry of Ukraine (10.1.05411357.010:2014) "The system of ensuring reliable and safe functioning of mine workings with anchor linings. General technical requirements".

The results of theoretical and experimental research in this field of mining deserve attention not only as a knowledge of the patterns of behavior of rocks, but although they outline ways to develop new advanced technical tools and technologies for mining.

Special attention should be paid to the results of experimental studies, which show that changes in the relation of the components of the stress state lead to changes in the nature of the extreme behavior of rocks by an increase both plastic and brittle properties.

It has been established that faulted rocks and coals under ultimate stress conditions are sensitive to any (shock, vibration, cyclic loads, wetting, etc.) even very weak additional impacts that change the processes of destruction from more energy-intensive to less energyintensive mechanisms of destruction and increase the decay modulus for rocks in a boundbroken condition, and decrease in residual strength for rocks in a broken condition.

\section{Disintegration of rock mass around underground workings}

The team of Russian scientists under the leadership of Academician E.I. Shemyakin experimentally established that under underground workings in rock mass, ring-shaped alternating parts of weakly broken and destroyed rocks are formed at the corresponding maximum stress state and great depths around the workings. The results were the subject of scientific discovery \#400 of the USSR [31].

The scientific value of the discovery is that it introduces fundamental changes in the idea of the condition, properties and behavior of a rock mass at great depths during workings. The discovery made it possible to create a scientific base for the development of theoretical models of the behavior of a rock mass under high stress conditions, to create a theory of the brittle fracture of geomaterials and instrumental methods for predicting the dynamic manifestations of rock pressure.

The practical significance of the discovery lies in the fact that, on its basis, fundamentally new methods have been developed and implement to predict and prevent rock bursts, penetration and fixation of underground workings and other.

The studies were conducted at the Institute of Mining of the Siberian Branch of the Academy of Sciences of the USSR and at the All-Union Scientific Research Institute of Mining Mechanics and Surveying.

The results of research on the development and detailing of certain aspects of theoretical and applied issues are widely covered in numerous scientific and technical publications [1, $31-37]$ and others.

Al the main aspects were quite fully elaborated in these works, including the field of problems of nonlinear geomechanics with one voice within the framework of the concept of academician M.A. Sadovsky on the block-hierarchical structure firm massif of rock. In 
[38], the authors confirm that in the sedimentary rocks of the Donbass coal deposits there is a phenomenon of zonal disintegration of rocks around the preparatory working, but this zonal disintegration is characterized by the nature of fluctuations in time and space.

In [39], using the nonequilibrium thermodynamics, the physical bases of zonal destruction of rocks near the mine workings were described. The evolution of the destruction of rocks, starting with the elastic state after the working and ending with a developed zonal structure, is described. The resulting relationships are illustrated by the results of a computational experiment.

The authors [40] showed the fractal nature of the coal-bearing massif and the nature of its destruction both in the vicinity of geological disturbances and around mine workings.

\section{Conclusions}

Currently, mathematical models based on classical methods of mathematical analysis, Euclidean geometry and continuum mechanics are used in geomechanics. Using such models, the rock mass behavior under small deformations is described by methods of plasticity, creep or hereditary-elastic medium. Typically, these models are based on two basic assumptions: the coal-bearing massif is a continuous medium; the functions describing the behavior of the medium are continuous and fairly smooth. Such formalization makes it possible to use a powerful mathematical apparatus - the theory of partial differential equations. However, existing trends in geomechanics associated with the variability of the physicomechanical properties of rocks, the integrity of the coalbearing massif and a number of other aspects show that its further development has to be associated with changes in the methodology for geomechanical problems, primarily the using of unconventional mathematical objects: fractal sets, geometric probabilities, nondifferentiable and singular functions, etc.

The destruction of rocks during compression has a columnar nature: cracks grow in the direction of uniaxial compression, which is inconsistent with the existing fracture mechanics basis. It is possible to overcome this discrepancies using the fractal ideas about the development of cracks at various scale levels.

The need for the prediction of the rock destruction requires in-depth study of the process of destruction, taking into account large-scale heterogeneities and structural features of the coal-bearing massif. In this regard, laboratory studies of the process of rock destruction at both micro and macroscopic levels with recording acoustic signals, electromagnetic emission pulses, etc., are of particular importance. Accumulation of damage under the rock loading is a fractal time series - a persistent impulse process characterized by the Hurst index.

The properties of rocks have significant variability, that leads to the use of probabilisticstatistical methods. Also, in geomechanics, there are fractal mechanical processes of a special kind that can spontaneously arise (rock bursts, sudden ejections of coal, rock and gas, etc.), or decay (brittle fracture in the vicinity of mine workings, lowering of the roof in the lavas of coal seams, etc.). To model such processes, it is necessary to use the modern probabilistic methods for detecting and predicting spontaneous arising and spontaneously decaying effects.

So, the fractal approach allows to explain using a different point of view the scale effect of strength in rocks, which cause is related to the mechanism of destruction, the structural and scale characteristics of the material and the geometry of the defective sets. This brings the geomechanical forecast of changes in the stress-strain state of the coal-bearing massif in the vicinity of mine workings to a qualitatively new level. 


\section{References}

1. Kurlenya, M.V., Oparin, V.N. (1999). Problemy nelineynoy geomechaniki. P.I. FTPRPI, (3), 12-26

2. Baron, L.I. (1977). Gornonehniligicheskoye porodovedeniye. Predmet i sposoby issledivaniy. Moskva: Nauka

3. Kartashov, Yu. M., Matveev, B.V., Miheev, G.V., Fadeev, A.B. (1979). Prochnost $i$ deformiruyemost gornyh porod. Moskva: Nedra

4. Usachenko, B.M., Cherednichenko, V.P., Golovchanskiy, I.Ye. (1990). Geomechanika ohrany vyrabotok v slabometamorfizirovannyh porodah. Kyiv: Naukova dumka

5. Baron, L.I., Kerekelitsa, L.G. (1974). Soprotivlyaemost gornyh porod otryvu. Kyiv: Naukova dumka

6. Timoshenko, S.P., Gooder, J. (1975). Teoriya uprugosti. Moskva: Nedra

7. Baklashov, I.V., Kartoziya, B.A. (1975). Mechanika gornyh porod. Moskva: Nedra

8. Usachenko, B.M. (1979). Svoystva porod i ustoychivost girnyh vyrabotok. Kyiv: Naukova dumka

9. Koyfman, M.I. (1962). O vliyaniyi razmerov na prochnost obraztsov gornyh porod. $V$ sbornike "Issledovaniye phiziko-mehanicheskih svoystv gornyh porod primenitelno $k$ zadacham upravleniya gornym davleniyem" Publishing House of the Academy of Sciences of the USSR, $6-14$.

10. Baklashov, I.V. (1988). Deformirovaniye i razrusheniye porodnyh massiviv. Moskva: Nedra

11. Petuhov, I.M., Linkov, A.M. (1983). Mehanika gornyh udarov i massiviv. Moskva: Nedra

12. Norel, B.K. (1982). Izmeneniye mehanicheskoy prochnosti ugolnogo plasta v massive. Moskva: Nauka

13. Salganik, R.L. Integralnye defekty, vyzyvayemye treshchinami. Analiticheskiye $i$ chislennye issledovaniya $v$ mehanike gorny horod. Novosibirsk, $37-39$.

14. Shashenko, A.N., Mayherchik, T., Sdvizhkova, E.A. (2005). Geomehanicheskiye protsessy v gornyh massivah. Dnipropetrovsk: Natsionalniy Hirnychiy Universytet

15. Ruppeneyt, K.V. (1975). Deformiruyemost massivov treshchinovatyh gornyh porod. Moskva: Nedra

16. Sedov, L.I. (1962). Vvedeniye v mehaniku sploshnoy sredy. Moskva: Fizmatgiz

17. Sedov, L.I.(1970). Mehanika sploshnoy sredy. (1), Moskva: Nauka

18. Germen, P. (1983). Kurs mehaniki sploshnoy sredy. Moskva: Vysshaya shkola

19. Deyneka, V.S., Sergienko, I.V. (2001). Modeli i metody resheniya zadach v neodnorodnyh sredah. NAS of Ukraine, Institute of Cybernetics by V.M. Glushkov, Kyiv: Naukova dumka

20. Sergienko, I.V., Deyneka, V.S. (2009). Sistemny analis mnogokomponentnyh raspredelennyh sistem. NAS of Ukraine, Institute of Cybernetics by V.M. Glushkov, Kyiv: Naukova dumka

21. Fisenko, G.L. (1976). Predelnoye sostoyaniye gornyh porod vokrug vyrabotok. Moskva: Nedra

22. Voloshyn, A.I., Bulat, A.F., Riabtsev, O.V., Koval, A.I. (2010). Metodologiya opredeleniya ratsionalnyh tehnologicheskih parametrov vedeniya gornyh porod. Ugol Ukrainy, (10), 15 - 18

23. Voloshyn, A.I., Bulat, A.F., Riabtsev, O.V., Savostiyanov, A.V. (2011). Tehnologiya strategicheskogo planirovaniya razvitiya gornyh rabot. Ugol, (2), $22-25$

24. Voloshyn, A.I., Riabtsev, O.V., Barabash, M.V., Vivcharenko, A.V., Koval, A.I. (2017). Obosnovaniye shyriny ugolnogo tselika mezhdu podgotovitelnoy vyrabotkoy i vyrabotannym prostranstvom otrabotannoy lavy. Ugol Ukrainy, (7-8), 8 - 14 
25. Voloshyn, A.I., Riabtsev, O.V., Koval, A.I., Skrypnik, K.Ye. (2012). Opredeleniye ratsionalnyh parametrov otrabotki lavy po faktoru gornogo davleniya. Ugol Ukrainy, (8), $4-7$

26. Voloshyn, A.I., Riabtsev, O.V., Ignatovich, Yu.N. (2014). K voprosu o mehanizme dezintegratsiyi gornyh porod vokrug gornyh vyrabotok. Scientific and technical support of mining production. (86), $88-96$

27. Voloshyn, A.I., Riabtsev, Morozov, Yu.A. (2017). Modelirovaniye protsessa razrusheniya gornyh porod po parametru povrezhdayemosti. Ugol Ukrainy, (1-2), 61 67

28. Stavrogin, A.N., Protosenya, A.G. (1985). Prochnost gornyh porod i ustoychivost vyrabotok na bolshih glubinah. Moskva: Nedra

29. Vinogradov, V.V. (1989). Geomehanika upravleniya sostoyaniyem massiva vblizi gornyh vyrabotok. Kyiv: Naukova dumka

30. Baklashov, I.V., Kartoziya, B.A. (1986). Mehanicheskiye protsessy v porodnyh massivah. Moskva: Nedra

31. Cherepanov, G.P. (2010). Mehanika razrusheniya i parapsihologoya. Prikladnaya mehanika, 2 (46), 138 - 141

32. Shemyakin, Ye.I., Kurlenya, M.V., Oparin, V.N., Reva, V.N., Glushyhin, F.P., Rozenbaum, M.A. (1992). Yavleniye zonalnoy dezintegratsiyi gornyh porod vokrug podzemnuh vyrabotok. Patent No 400 USSR. Publ. in BI, 1, 3

33. Shemyakin, Ye.I., Fisenko, G.L., Kurlenya, M.V., Oparin, V.N. (1986). Zonalnaya dezintegratsiya gornyh porod vokrug podzemnuh vyrabotok. FTPRPI, Part 1: Data of field observations, (3), $3-15$

34. Shemyakin, Ye.I., Fisenko, G.L., Kurlenya, M.V., Oparin, V.N. (1986). Zonalnaya dezintegratsiya gornyh porod vokrug podzemnuh vyrabotok. FTPRPI, Part 2: Destruction of rocks on models of equivalent materials, (4), $3-12$

35. Shemyakin, Ye.I., Fisenko, G.L., Kurlenya, M.V., Oparin, V.N. (1987). Zonalnaya dezintegratsiya gornyh porod vokrug podzemnuh vyrabotok. FTPRPI, Part 3: Theoretical representations, (1), $3-8$

36. Shemyakin, Ye.I., Fisenko, G.L., Kurlenya, M.V., Oparin, V.N. (1987). Zonalnaya dezintegratsiya gornyh porod vokrug podzemnuh vyrabotok. FTPRPI, Part 4: Prakticheskiye prilozheniya, (4), 3 - 9

37. Chanyshev, A.I., Belousova, O.E. (2009). Ob odnoy interpretatsiyi zonalnoy desintegratsiyi massiva gornyh porod vokrug vyrabotok. Fizicheskaya mezomehanika, (12), $89-99$

38. Metlov, L.S., Morozov, A.F., Zborschik, M.P. (2002). Fizicheskiye osnovy mehanizma zonalnogo razrusheniya porod v okrestnosti gornoy vyrabotki. FTPRPI, (2), 55 - 60

39. Guzev, M.A., Paroshin, A.A. (2001). Neyevklidova model zonalnoy dezintegratsiyi gornyh porod vokrug podzemnoy vyrabotki. PMTF, 1 (42), 147 - 156

40. Morozov, A.F., Yuskevich, A.M. (1991). Fluktuatsiyi zonalnoy dezintegratsiyi osadochnyh porod vokrug podgotovitelnoy vyrabotki. Ugol Ukrainy, (7), 36 - 39

41. Kaido, I.I. (2009). Klasternaya model yavleniya zonalnoy dezintegratsiyi massiva vokrug podzemnyh vyrabotok. Moscow State Mining University, SIAL, (6), 48 - 57

42. Bulat, A.F., Dyrda, V.I. (2005). Fractaly v geomehanike. Kyiv: Naukova dumka 